\title{
International
} Journal of Medical and Exercise Science

(Multidisciplinary, Peer Reviewed and Indexed Journal)

ORIGINAL ARTICLE

\section{A COMPARATIVE STUDY OF AQUATIC TRAINING EXERCISES OVER FREE EXERCISE TECHNIQUE ON SHOULDER FUNCTION AMONG PERIARTHRITIS SHOULDER PATIENTS}

Search engine:

www.ijmaes.org

\section{Jibi Paul ${ }^{1}$, Louis Christy Maxwell ${ }^{2 *}$, Ena Dulom², B D Mark Raj ${ }^{2}$, Moorthy A}

\section{Author:}

${ }^{1}$ Pofessor, Faculty of Physiotherapy, Dr.MGR. Deemed to be University, Chennai, Tamilnadu, India.

${ }^{2}$ B.P.T. Graduate, Faculty of Physiotherapy, Dr.MGR. Deemed to be University, Chennai, Tamilnadu, India

${ }^{3}$ Asst.Professor, Faculty of Physiotherapy, Dr.MGR. Deemed to be University, Chennai, Tamilnadu, India.

Corresponding Author:

${ }^{2 *}$ B.P.T. Graduate, Faculty of Physiotherapy, Dr.MGR. Deemed to be University, Chennai, Tamilnadu, India.

Mail id: louismaxo336@gmail.com

\section{ABSTRACT}

Background of the Study: Shoulder is a very complex joint crucial to many activities of daily living. Decrease shoulder mobility is a serious clinical finding in Frozen shoulder or Adhesive capsulitis, which affects 2-5\% of the population and is most common in 40-60-year age group. The aim of the study is to compare the aquatic training exercise over free exercise on shoulder function among pa patients. Methodology: This was an Experimental study with 30 male and female players. They were divided into two groups by simple sampling method, 15 players in each group. Age group of the subjects was 40 to 60 years. Group A players were trained with aquatic training. Group B players were trained with shoulder Free Exercise. Both the group players are trained for 4 weeks and 3 sessions in a week. Intervention was done in swimming pool at Rajiv Gandhi stadium, Chennai and free exercise therapy executed at Physiotherapy department ACS Medical College and Hospital, Chennai. Outcome Measures were, Range of Movement measured by Goniometer, Pain measured by Visual Analog Scale and Function was measured by (SPADY) Shoulder pain and disability index. Result: On comparing Pre-test and Post-test within and between Group A \& Group B on Visual Analog Scale, SPADI \& Shoulder Range of Motion shows significant difference in Mean values at $P \leq 0.001$. Conclusion: Study concluded that the subjects treated with Aquatic Exercise showed more improvement than Free Exercise in shoulder pain, range of movement and function.

Keywords: Frozen Shoulder, Aquatic Training, Range of Movement, Shoulder Pain And Disability Index

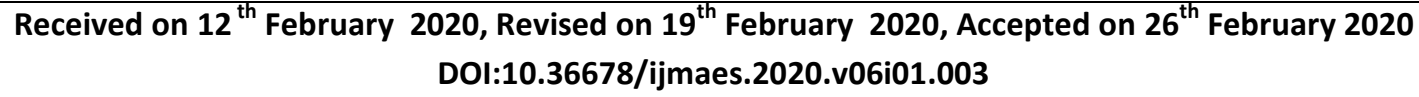




\section{INTRODUCTION}

The shoulder is a very complex joint that is crucial to many activities of daily living. Decrease shoulder mobility is a serious clinical finding. Frozen shoulder or Adhesive capsulitis affects $2-5 \%$ of the population and is most common in 40-60-year age group ${ }^{1,2}$.

Adhesive capsulitis is a condition characterized by progressive loss of both active and passive range of motion. The patients with adhesive capsulitis experience more pain compared to other shoulder conditions. The movements are usually restricted to a characteristic pattern with proportional greater passive loss of shoulder shoulder external rotation and abduction than any other movement ${ }^{3,4}$.

The Frozen shoulder can be due to idiopathic or post traumatic causes, but the term adhesive capsulitis includes female gender, age older than40years, diabetes, thyroid disease, strokes, presence of autoimmune disorders ${ }^{5,6}$.

Three stages of adhesive capsulitis are; 1 ) Freezing Stage: Mainly characterized by severe pain in the shoulder even at rest. There is also decrease in shoulder external rotation and abduction ROM. 2) Frozen Stage: Pain is no longer present at rest but only with movement. Pain gradually subsides but stiffness is marked lasting 4 to 12 months. 3) Thawing Stage: There is slow but progressive recovery of ROM. The freezing stage in this stage pain becomes worse and range of motion becomes more restricted. This phase lasts between 3 to 9 months and is characterized by an acute synovitis of the glenohumeral joint ${ }^{7}$.

The second stage is called the frozen or transitional stage in this there is a lack of synovial fluid, which normally helps the shoulder joint, a ball and socket move by lubricating the gap between the humerus and the socket in the shoulder blade. The shoulder capsule thickens, swells, and tightens due to bands of scar tissue (adhesions) that have formed inside the capsule. As a result, there is less movement in the joint for the humerus, making movement of the shoulder stiff and painful. The thawing stage is the final stage during which range of motion gradually improves over several months to years ${ }^{8,9}$.

\section{METHODOLOGY}

This was an Experimental study with 30 male and female players. They were divided into two groups by simple sampling method, 15 players in each group. Age group of the subjects was 40 to 60 years. Group A players were trained with aquatic training exercise. Group B players were trained with Free exercise.

Both the group players are trained for 4 weeks and 3 sessions in a week. Aquatic training was done in swimming pool at Rajiv Gandhi stadium, Chennai and exercise therapy executed at Physiotherapy department ACS Medical College and Hospital, Chennai. Outcome Measures were, Range of Movement measured by Goniometer, Pain measured by Visual Analog Scale and Function was measured by (SPADY) Shoulder pain and disability index.

\section{Intervention}

\section{Group B trained with Free Exercise For Periarthritis Shoulder}

1) Pendulum Stretch: Procedure: Relax your shoulder, Stand and lean over slightly, allowing the affected arm to hang down. Swing the arm in a circle about a foot in 
diameter. Prefer 10 revolution in each direction, over a day.

2) Towel Stretch : Procedure:Hold one end of a three -foot long towel behind your back and grab the opposite end withyour other hand. Hold the towel in horizontal position. Use the good arm to pull the affected arm upward to stretch it.Do this 10 to 20 times a day.

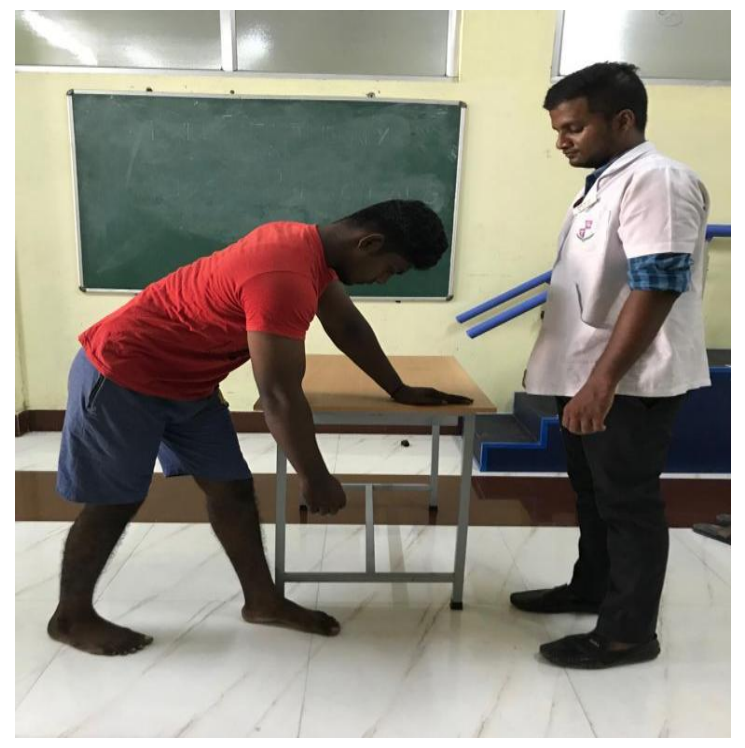

Figure 1. Patient performing Pendulum Stretch

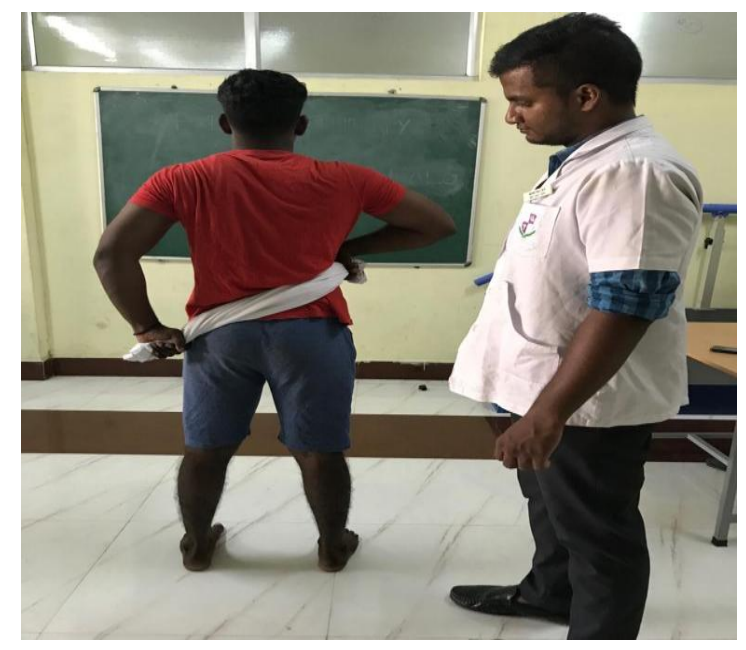

Figure 2. Patient performing Towel Stretch
3) Finger walk : Procedure: Face a wall three quarters of an arms length away. Reach out and touch the wall at waist level with the finger tips of the affected arm.

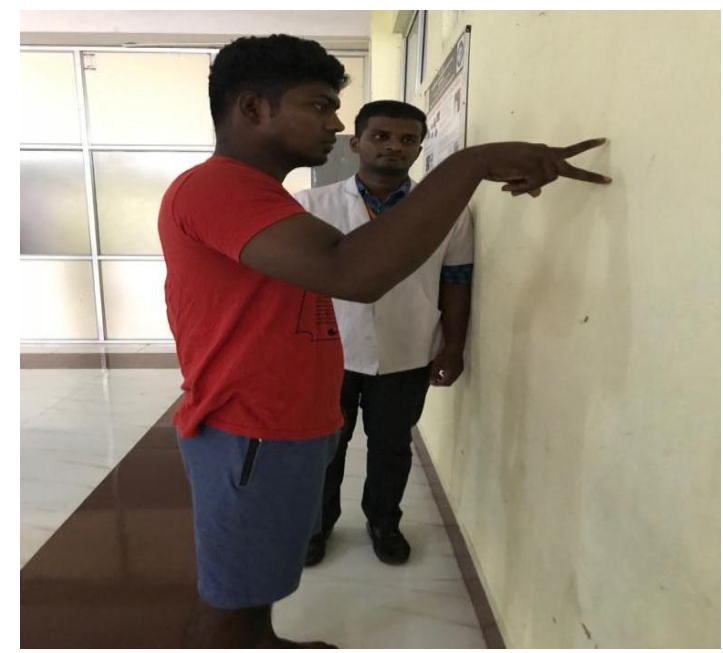

Figure 3. Patient performing Finger walk

4) Cross Body Reach : Procedure: Patient in sit or standing position. Use patients good arm to lift the affected arm at the elbow and bring it up and across your body,exerting gentle pressure to stretch the shoulder. Hold the stretch for 15 to 20 seconds .do this 10 to 20 times per day.

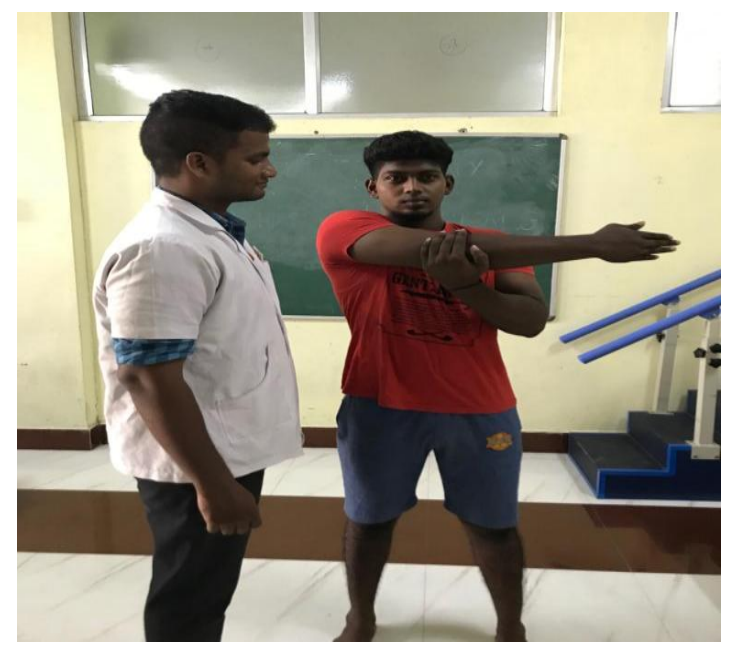

Figure 4. Patient performing Cross Body Reach 
5) Armpit stretch: Procedure: Using your good arm to lift the affected arm out a shelf about breast high. Gently bend your knees ,opening up the armpit. Deepen your knees bend slightly, gently stretching the armpit and then straighten.

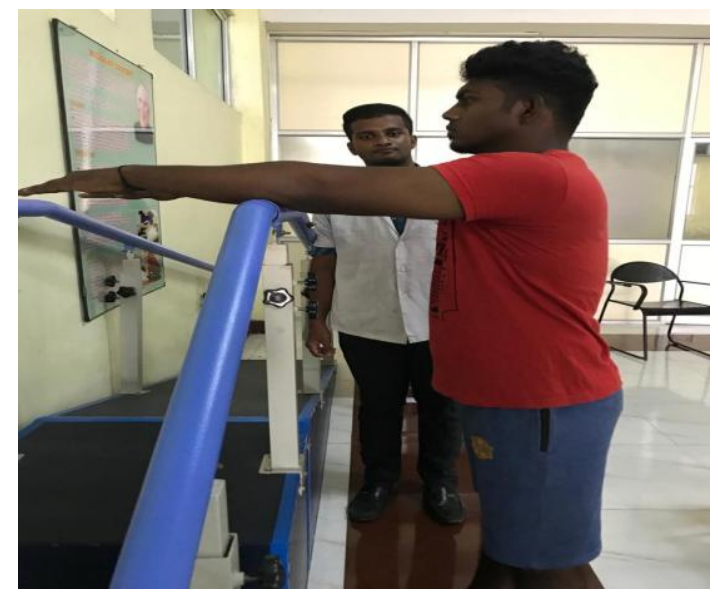

Figure 5. Patient performing Armpit stretch

6) Outward Rotation : Procedure: Hold a rubber exercise band between your hands with your elbow at a 90 degree angle close to your sides. Rotate the lower part of the affected arm outward two or three inches and hold for five seconds.repeat 10 to 15 times in a day.

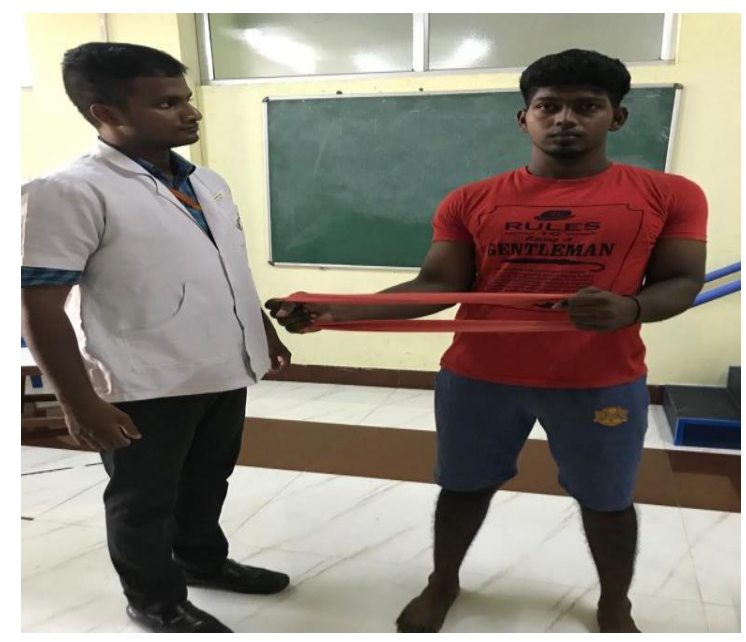

Figure 6. Patient performing Outward Rotation
7) Inward Rotation: Procedure:-stand nexr ro a closed door and hook one end of a rubber exercise band across the locknob.hold the other end with the hand of the affected arm,holding your elbow at a 90 degree angle.pull the band towards your body two or three inches and hold for two seconds.

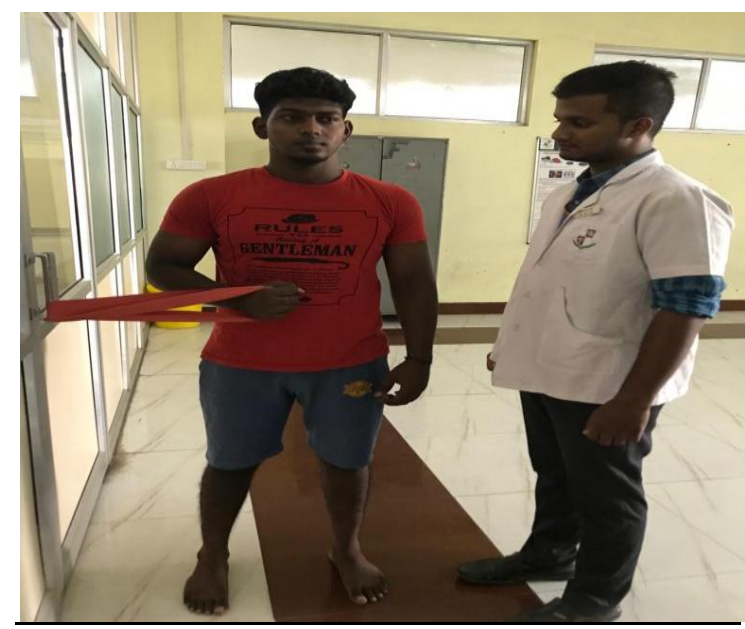

Figure 7. Patient performing Inward Rotation

\section{Group A trained with Aquatic Exercise}

1) Aquatic exercise for Gleno-humeral joint restricted abduction: Position of the Patient was in Prone lying. Position of The Therapist was stand by side of the patient, places her hand over the top of the shoulder to palpate for the motion.

Procedure: Therapist makes the patient to move his/her shoulder passively to the restricted position. Therapist stabilized the shoulder joint, holds along the restricted position and contracts away from the Barrier. the therapist ask the the patient to move the affected limb in the restricitedside.till the target is achieved.

2) Aquatic Exercise For Gleno Humeral Joint Restricted External Rotation: Position of The 
Patient was in Prone lying. Position of The Therapist was stand by side of the patient.

Procedure: Make the patient to move his/her shoulder passively to the restricted position. Therapist stabilized the shoulder, holds along the restricted position l.e. towards external rotation and contracts away from the barrier. Ask the patient to bring it for internal rotation with $1 / 3$ of maximal effort. Hold for 6-7 secs and allow the patient to relax for 2 secs and then repeat the same after every 2 minutes for consecutive weeks.

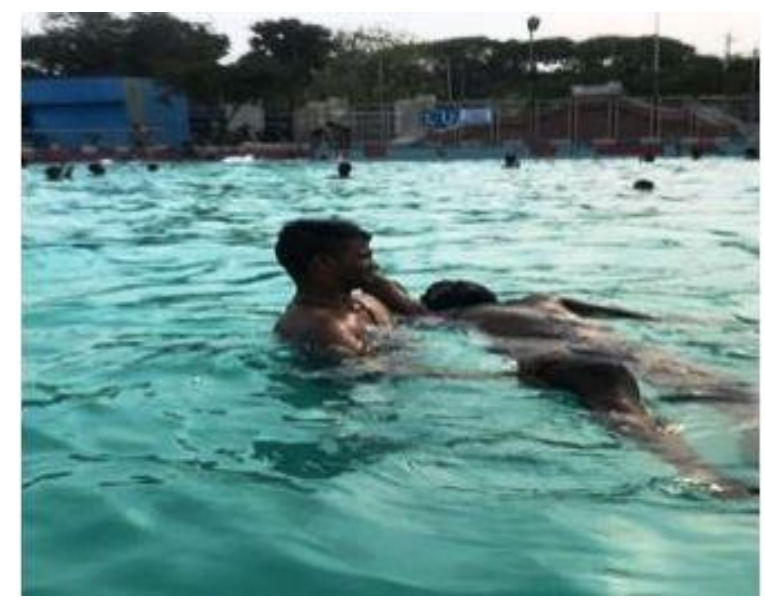

Figure 8. Patient performing shoulder restricted restricted abduction and External Rotation

\begin{tabular}{|c|c|c|c|c|c|c|}
\hline \multirow{2}{*}{ VAS } & \multicolumn{2}{|c|}{ PRE TEST } & \multicolumn{2}{c|}{ POST TEST } & \multirow{2}{*}{ SIGNIFICANCE } \\
\cline { 2 - 5 } & MEAN & S.D & MEAN & S.D & t - TEST & \\
\hline \multirow{2}{*}{ GROUP- A } & 6.33 & .816 & 2.26 & .798 & 34.40 & $.000^{* * *}$ \\
\hline GROUP-B & 6.26 & .883 & 2.13 & .743 & 21.53 & $.000^{* * *}$ \\
\hline
\end{tabular}

Table 1. Comparison of Visual Analog Scale score on pre and post test wihin Group-A and Group-B

This table shows that there is significant difference in Pre-Test and Post-Test values between Group $A$ and Group B ( $P>0.05)$.

\begin{tabular}{|c|c|c|c|c|c|c|}
\hline \multirow{2}{*}{ SPADI } & \multicolumn{2}{|c|}{ PRE TEST } & \multicolumn{2}{c|}{ POST TEST } & \multirow{2}{*}{ t - TEST } & \multirow{2}{*}{ SIGNIFICANCE } \\
\cline { 2 - 6 } & MEAN & S.D & MEAN & S.D & \\
\hline GROUP- A & 63.32 & 7.65 & 29.69 & 4.55 & 16.91 & $.000^{* * *}$ \\
\hline GROUP-B & 63.93 & 9.82 & 37.34 & 10.04 & 14.13 & $.000^{* * *}$ \\
\hline
\end{tabular}

Table 2. Comparison of SPADI score on pre and post test within Group - A and Group - B

This table shows that there is significant difference in pre-test values between Group A \& Group B $(P>0.05)$. 


\begin{tabular}{|c|c|c|c|c|c|c|c|}
\hline \multirow{2}{*}{$\begin{array}{c}\text { SHOULDER } \\
\text { ROM }\end{array}$} & \multicolumn{2}{|c|}{ PRE TEST } & \multicolumn{2}{c|}{ POST TEST } & \multirow{2}{*}{$\begin{array}{c}\text { Mean } \\
\text { Diff }\end{array}$} & t - TEST & SIGNIFICANCE \\
\cline { 2 - 7 } & MEAN & S.D & MEAN & S.D & & \\
\hline ABDUCTION & 83.73 & 6.02 & 106.53 & 8.50 & 22.8 & -9.96 & $.000^{* * *}$ \\
\hline $\begin{array}{c}\text { EXTERNAL } \\
\text { ROTATION }\end{array}$ & 26.24 & 2.69 & 40.26 & 3.71 & 14.02 & -10.96 & $.000^{* * *}$ \\
\hline
\end{tabular}

Table 3. Comparison of ROM on Pre and Post test values within Group -A

There is a statistically significant difference between the pre-test and post-test values within Group A $(P \leq 0.001)$.

\begin{tabular}{|c|c|c|c|c|c|c|c|}
\hline \multirow{2}{*}{$\begin{array}{c}\text { SHOULDER } \\
\text { ROM }\end{array}$} & \multicolumn{2}{|c|}{ PRE TEST } & \multicolumn{2}{c|}{ POST TEST } & $\begin{array}{c}\text { Mean } \\
\text { Diff }\end{array}$ & t - TEST & SIGNIFICANCE \\
\cline { 2 - 8 } & MEAN & S.D & MEAN & S.D & $-000^{* * *}$ \\
\hline $\begin{array}{c}\text { ABDUCTION } \\
\text { ROTATION }\end{array}$ & 23.06 & 4.13 & 107.26 & 8.04 & 24.2 & -10.93 & $.000^{* * *}$ \\
\hline
\end{tabular}

Table 4 Comparison of ROM on Pre and Post test values within Group -B

There is a statistically significant on pre-test and post-test values within Group $B(P \leq 0.001)$.

\begin{tabular}{|c|c|c|c|c|c|c|c|}
\hline \multirow{2}{*}{ VAS } & \multicolumn{2}{|c|}{ GROUP - A } & \multicolumn{2}{c|}{ GROUP - B } & \multirow{2}{*}{} & \multirow{2}{*}{ SIGNIFICANCE } \\
\cline { 2 - 7 } & MEAN & S.D & MEAN & S.D & t - TEST & df & SIG \\
\hline PRE TEST & 6.33 & .816 & 6.26 & .883 & .215 & 28 & .832 \\
\hline POST TEST & 2.26 & .798 & 2.13 & .743 & .473 & 28 & .640 \\
\hline
\end{tabular}

Table 5. Comparison of Visual Analog Scale score on pre and post test between Group-A and Group-B

This table shows NO statistically significant difference in pre and post-test values between Group A \& Group B $(P \leq 0.05)$. But higher mean difference in Group $A(6.33,2.26)$ Shows better effect than Shows better effect than mean difference Group B $(6.26,2.13)$. 


\begin{tabular}{|c|c|c|c|c|c|c|c|}
\hline \multirow[b]{2}{*}{ SPADI } & \multicolumn{2}{|c|}{ GROUP - A } & \multicolumn{2}{|c|}{ GROUP - B } & \multirow[b]{2}{*}{$t$ - TEST } & \multirow[b]{2}{*}{ df } & \multirow[b]{2}{*}{ SIGNIFICANCE } \\
\hline & MEAN & S.D & MEAN & S.D & & & \\
\hline $\begin{array}{c}\text { PRE } \\
\text { TEST }\end{array}$ & 63.32 & 7.65 & 63.93 & 9.82 & -0.189 & 28 & .852 \\
\hline $\begin{array}{l}\text { POST } \\
\text { TEST }\end{array}$ & 29.69 & 4.55 & 37.34 & 10.04 & -2.68 & 28 & $.012 * *$ \\
\hline
\end{tabular}

Table 6. Comparison of SPADI score on pre and post test between Group A and Group B

This table shows statistically significant difference in pre and post-test values between Group A \& Group B ( $\mathrm{P} \leq 0.05)$. Group A with mean difference 33.630, shows better effect than Group B mean difference 26.53.

\begin{tabular}{|c|c|c|c|c|c|c|c|}
\hline \multirow{2}{*}{ ROM } & \multicolumn{2}{|c|}{ GROUP - A } & \multicolumn{2}{c|}{ GROUP - B } & & \\
\cline { 2 - 7 } & MEAN & S.D & MEAN & S.D & t - TEST & df & SIGNIFICANCE \\
\hline $\begin{array}{c}\text { PRE } \\
\text { (ABD) }\end{array}$ & 83.06 & 4.13 & 83.73 & 6.02 & -0.353 & 28 & $.727^{*}$ \\
\hline $\begin{array}{c}\text { POST } \\
\text { (ABD) }\end{array}$ & 107.26 & 8.04 & 106.53 & 8.50 & 0.242 & 28 & $.810^{*}$ \\
\hline $\begin{array}{c}\text { PRE } \\
\text { (E.R) }\end{array}$ & 26.86 & 3.09 & 26.46 & 2.69 & 0.378 & 28 & $.708^{*}$ \\
\hline $\begin{array}{c}\text { POST } \\
\text { (E.R) }\end{array}$ & 42.33 & 4.38 & 40.26 & 3.71 & 1.39 & 28 & $.175^{*}$ \\
\hline
\end{tabular}

Table 7. Comparison of ROM on Pre and Post test values between Group A and B

There is NO statistically significant difference between the pre-test and post-test values between Group $A$ and $B(P \leq 0.05)$. But Group A with mean difference 24.2, 15.47, shows better effect than Group B mean difference 22.8, 13.08. Respectively on abduction and external rotation. 


\section{RESULT}

On comparing the Mean values of Group A \& Group B on Visual Analog Scale, both the groups showed decrease in the pain intensity based on post-test Mean values in which (Group A) shows 2.26 \& (Group B) 2.13 Therefore no significant difference was found between post-test mean values at $\mathrm{P}>0.05$ (Table 1).

On comparing the Mean values of Group A \& Group B on SPADI score, both the groups showed significant decrease in the post-test Mean values but (Group A) shows 29.69 which has the Lower Mean value is effective than (Group B) 37.34 at $\mathrm{P} \leq 0.05$ (Table 2).

On comparing the Mean values within the Group A \& Group B on Shoulder Range of Motion (Abduction \& External Rotation) both the group showed increase in the post-test Mean values in which (Group A) shows 107.26 \& 42.33 degree (Group B) 106.53 \& 40.26 degree respectively. Therefore no significant difference was found between post-test mean values at $\mathrm{P}>0.05$ (Table 3 and 4).

On comparing Pre-test and Post-test within Group A \& Group B on Visual Analog Scale, SPADI \& Shoulder Range of Motion shows significant difference in Mean values at $P \leq$ 0.001 .

Table-5. Comparison of Visual Analog Scale score on pre and post test between Group-A and Group-B. This table shows NO statistically significant difference in pre and post-test values between Group A \& Group B ( $P \leq 0.05)$. But higher mean difference in Group A (6.33, 2.26) Shows better effect than Shows better effect than mean difference Group B (6.26, 2.13).

Table -6. Comparison of SPADI score on pre and post test between Group A and Group B. This table shows statistically significant difference in pre and post-test values between Group A \& Group $B \quad(P \leq 0.05)$. Group $A$ with mean difference 33.630, shows better effect than Group B mean difference 26.53 .

Table-7. Comparison of ROM on Pre and Post test values between Group A and B. There is NO statistically significant difference between the pre-test and post-test values between Group A and B ( $P \leq 0.05)$. But Group A with mean difference 24.2, 15.47, shows better effect than Group B mean difference 22.8, 13.08. Respectively on abduction and external rotation.

\section{DISCSSION}

This study is done to investigate, to find the effectiveness of aquatic training and free exercise on functional ability, pain and Range of motion of shoulder in patients with phase II Adhesive capsulitis.

In Adhesive capsulitis, there is loss of range of motion in all planes and pain persists for months. In subacute stage pain during movement of shoulder joint is more evident. In this study pain was measured on VAS Scale, range of motion by Goniometer and functional impairment was measured on Shoulder Pain and Disability Index.

The result of the study stated that there is statistically significant improvement in VAS, Range of motion and functional disability after 15 days training on aquatic training and free 
shoulder exercise. The study observed that on comparing both the Groups, there was statistically difference between Group $A$ and Group B in Shoulder pain, ROM and functional disability index .

The age of participants was taken between 4060 years both male and female in both the groups. The mean age in group $A$ is $54.83 \pm 4$.31 and in Group B it was 53.05 5 5.02.

According to Robert Marske et al in the second or subacute stage of adhesive capsulitis shoulder pain does not necessarily worsen but there is pain at end of ROM, use of arm is limited causing muscular disuse. The primary role of mobilization is to restore joint play and facilitate joint movement by restoring arthrokinematics. The biomechanical effect manifests itself when forces are directed towards resistance but within limit of patient's tolerance ${ }^{10,11}$.

The Mechanical changes may include breaking up adhesion in capsule, collagen realignment and improving interfibre glide when specific movement stress the specific part of capsular tissue ${ }^{12}$.

The aquatic exercise has an effect in reducing pain, increasing ROM and functional ability in patients with Adhesive capsulitis ${ }^{13}$.

The aquatic exercise can stretches were effective in treating Range of motion especially external rotation and abduction in patients with periarthritis shoulder ${ }^{14}$.

The study shows that aquatic exercise beneficial for decreasing pain, has vast effect on increasing Range of motion and functional ability in patients with periarthritis of shoulder ${ }^{15}$.
Ethical Clearance: Ethical clearance has obtained from Faculty of Physiotherapy, DR. MGR Educational and Reasearch Institute, Chennai to conduct this study with reference number: C-21/ PHSIO/ IRB/ 2018-2019 dated 08/01/2019.

Conflict of interest: There was no conflict of interest to conduct this study.

Fund for the study: It was a self financed study.

\section{CONCLUSION}

The Study concluded that the subjects treated with Aquatic Exercise And Free Exercise showed more effective in improvement of shoulder pain, function and range of movement. Mulligan technique also shown improvement in shoulder pain and disability and Range of motion (ROM).

Limitation of the Study: The sample size of this study was small. The study was for a Short duration and performed only for subjects with Periarthritis shoulder.

Recommendation of the Study: This study can conduct with different age groups. The sample size can be increased in upcoming studies.

\section{REFERENCES}

1. Pink MM, Tibone JE. (2000). The painful shoulder in the swimming athlete. Orthop Clin North Am., 31:247-61.

2. Wolf $B R$, Ebinger $A E$, Lawler $M P$, et al. (2009). Injury patterns in division I collegiate swimming. Am J Sports Med., 37:2037-42.

3. Bak K. (2010). The practical management of swimmer's painful shoulder: etiology, 
diagnosis, and treatment. Clin J Sport Med., 20: 386- 90.

4. Wanivenhaus F, Fox AJ, Chaudhury S, et al. (2012). Epidemiology of injuries and prevention strategies in competitive swimmers. Sports Health, 4: 246-51.

5. Tate A, Turner GN, Knab SE, et al. (2012). Risk factors associated with shoulder pain and disability across the lifespan of competitive swimmers. J Athl. Train., 47: 149-58.

6. McKenna L, Straker L, Smith A. (2012). Can scapular and humeral head position predict shoulder pain in adolescent swimmers and non-swimmers? J Sports Sci., 30: 1767-76.

7. Wymore L, Fronek J. (2015). Shoulder functional performance status of national collegiate athletic association swimmers: baseline Kerlan-Jobe orthopedic clinic scores. Am J Sports Med;43:1513-7.

8. Beach ML, Whitney SL, Dickoff-Hoffman S. (1992). Relationship of shoulder flexibility, strength, and endurance to shoulder pain in competitive swimmers. J Orthop Sports Phys Ther., 16: 262-8.

9. Heinlein S A, Cosgarea A J. (2010). Biomechanical considerations in the competitive swimmer's shoulder. Sports Health, 2: 519-25.

10. Hill L, Collins M, (2015). Posthumus M. Risk factors for shoulder pain and injury in swimmers: a critical systematic review. Phys Sports Med., 43: 412-20.

11. Hibberd EE, Laudner K, Berkoff DJ, et al. (2016).Comparison of upper extremity physical characteristics between adolescent competitive swimmers and nonoverhead athletes. J Athl Train., 51: 65-9.

12. Bak K, Magnusson SP. (1997). Shoulder strength and range of motion in symptomatic and pain-free elite swimmers. Am J Sports Med., 25: 454-9.

13. Harrington S, Meisel C, Tate A. (2014). A cross-sectional study examining shoulder pain and disability in division I female swimmers. J Sport Rehabil, 23: 65-75.

14. McMaster WC, Roberts A, Stoddard T. A (1998) Correlation between shoulder laxity and interfering pain in competitive swimmers. Am J Sports Med.,26: 83-6.

15. Zemek M J, Magee D J. (1996). Comparison of glenohumeral joint laxity in elite and recreational swimmers. Clin J Sport Med., 6: 40-7.

\section{Citation:}

Jibi Paul, Louis Christy Maxwell, et al (2020). A comparative study of aquatic training exercises over free exercise technique on shoulder function among periarthritis shoulder patients, International Journal of Medical and Exercise Science; 6 (1); 677-685. 